\title{
Preparation and ionic conductive mechanism of novel electrolyte for automobile oxygen sensor
}

\author{
Peng Liu ${ }^{1, \text { a }}$, Jiangrong Kong ${ }^{2}$, Xianfeng Yang $^{1}$, and Qicheng Liu ${ }^{1}$ \\ ${ }^{1}$ School of Physics and Electronics Science, Changsha University of Science and Technology, \\ Hunan Province, Changsha 410114, P. R. China \\ ${ }^{2}$ College of Chemistry and Chemical Engineering, Central South University, Changsha 410083, P. R. \\ China \\ aemail: Isoccerp@hotmail.com (Corresponding author)
}

Keywords: Oxygen sensor; samarium doped ceria; ionic conductive mechanism; electrochemical impedance spectroscopy

\begin{abstract}
Nano-sized samarium doped ceria (SDC) material was synthesized through a sol-gel method in order to improve the intermediate-temperature performance of solid electrolyte for automobile oxygen sensor. The ionic conductive behavior of the electrolyte was analyzed on the basis of electrochemical impedance spectroscopy (EIS) test, and the interaction of working temperature, defect microstructure and ionic conductivity was investigated. Accordingly, the SDC displayed an ionic conductivity of $0.029 \mathrm{~S} \mathrm{~cm}^{-1}$ at $750{ }^{\circ} \mathrm{C}$. It was suggested that the nano-crystalline could shorten the transfer distance of the charge carriers. Furthermore, the structural change of the polycrystal boundaries with the temperature was a key factor which promoted the oxygen ionic conductivity.
\end{abstract}

\section{Introduction}

Oxygen sensor is a key component in the control system of electronic fuel injection engine, which regulates the air-fuel ratio by detecting the oxygen concentration in the automobile exhaust. As well known, the sensitivity of the oxygen sensor is associated with the oxygen ionic conductivity of the solid electrolyte. In terms of the ionic conductivity, the applicability of traditional zirconia-based electrolyte was restricted at the intermediate-temperature region $\left(600 \sim 750{ }^{\circ} \mathrm{C}\right)$. Therefore, novel oxygen sensitive materials are demanded to achieve the dual purposes of rapid response and low-temperature operation [1-4].

Ceria is a promising material as the solid electrolyte. Doping of trivalent element in ceria generates more oxygen vacancies for the oxygen ionic conduction [5-9]. However, the electrical performance of the oxygen sensor electrolyte is determined by the size and the structure of the polycrystalline. The powder prepared through solid state method mainly consists of micro-sized particles, which is difficult to result in a dense electrolyte substrate. And the theoretical research on ionic conduction does not pay much attention to the change of the defect microstructure with the temperature [10 12] In this work, nano-sized samarium doped ceria (SDC) was synthesized via a sol-gel method. Furthermore, the influence mechanism of operation temperature and defect microstructure on the kinetic behavior of the charge carriers was investigated in combination with an electrochemical impedance measurement [13].

\section{Experimental}

Preparation of SDC powder and electrolyte $\mathrm{Sm}\left(\mathrm{NO}_{3}\right)_{3}$ and $\mathrm{Ce}\left(\mathrm{NO}_{3}\right)_{3}$ were mixed with a mole ratio of 1:4 and dissolved in an aqueous ethanol solution. Citric acid, as the chelating agent, was added into the nitrate with a continuous stirring at $70{ }^{\circ} \mathrm{C}$. Then, the colloidal solution was transformed into the gel by evaporating the dispersant at $120{ }^{\circ} \mathrm{C} . \mathrm{Ce}_{0.8} \mathrm{Sm}_{0.2} \mathrm{O}_{1.9}$ powder was attainable by calcining the gel precursor at $700{ }^{\circ} \mathrm{C}$ for $2 \mathrm{~h}$. XRD test was performed by a D/max-rB X-ray diffractometer (Rigaku Corporation, Japan) to examine the phase and the composition. The particle size distribution of the 
powder was analyzed by a Zetaplus Zeta Potential \& Particle Size Analyzer (Brookhaven Instruments Corporation, USA). The SDC powder was bonded with 4 wt. \% polyvinylalcohol (PVA) solution and press-molded at $200 \mathrm{MPa}$. Subsequently, the green compact was sintered at $1400{ }^{\circ} \mathrm{C}$ for $4 \mathrm{~h}$. The silver leads were fastened on both sides of the electrolyte substrate with the sintered silver slurry and sintered at $700{ }^{\circ} \mathrm{C}$ for $1 \mathrm{~h}$.

Investigation of ionic conductive mechanism The diffusion kinetics of the oxygen vacancy was analyzed to determine the relationship between ionic conductivity and working temperature. Electrochemical impedance spectroscopy (EIS) of the solid electrolyte was measured at the open circuit voltage from $600{ }^{\circ} \mathrm{C}$ to $750{ }^{\circ} \mathrm{C}$ by a CHI660B Electrochemistry Workstation (Shanghai Chenhua Instruments Corporation, China). Moreover, the spectra diagrams were analyzed with fitting software, ZSimpWin. The oxygen ionic conductivities of the electrolyte at different temperatures were calculated on the basis of EIS results.

\section{Results and Discussion}

Crystal phase and size of as-received powder XRD pattern of SDC powder sample is presented in Fig. 1. It can be observed that the structure of the as-prepared powder is consistent with the fluorite $\mathrm{CeO}_{2}$. However, the angular position of the diffraction peaks offsets in comparison with the standard pattern of $\mathrm{CeO}_{2}$. The peak-shift indicates the defect of the $\mathrm{CeO}_{2}$ lattice, which is attributed to the partial substitution of Ce by Sm. Nevertheless, Sm-doping does not change the inherent face-centered cubic structure of $\mathrm{CeO}_{2}$. The crystal size is estimated according to Debye-Scherrer's formula [14]: The spacing of (111), (200), (220) and (311) interplane is $10.4 \mathrm{~nm}, 11.9 \mathrm{~nm}, 11.1 \mathrm{~nm}$ and $10.5 \mathrm{~nm}$, respectively. The transfer distance of the charge carriers in the grain is significantly shortened as the small crystal size.

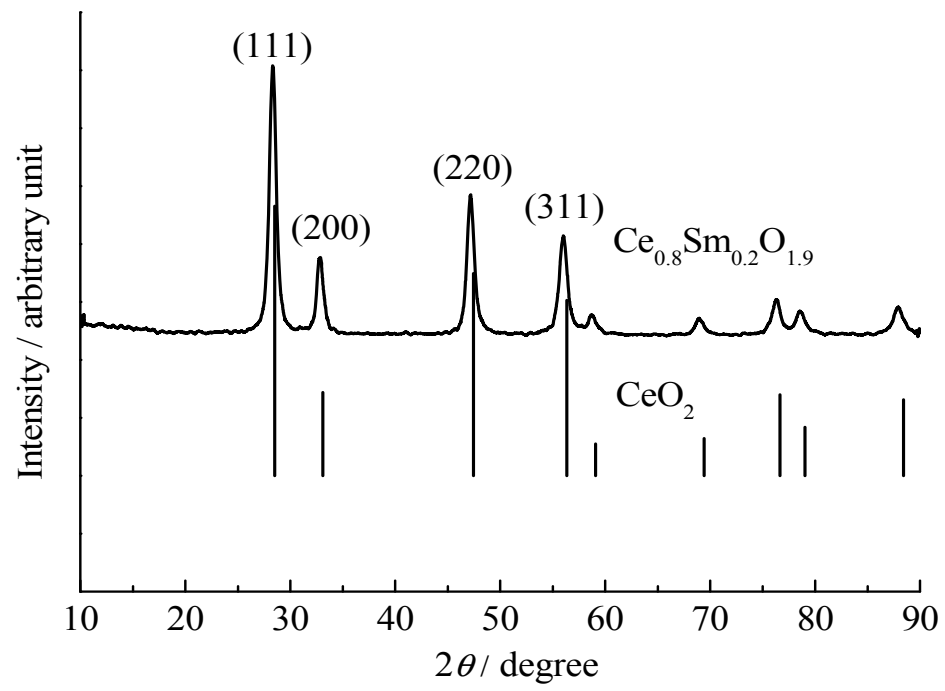

Fig. 1 XRD patterns of standard $\mathrm{CeO}_{2}$ and SDC sample

Ionic conductive mechanism of electrolyte Nyquist diagrams of SDC electrolyte at different temperatures are illustrated in Fig. 3. Each spectrum uniformly presents two capacitance arcs which are associated with the interfacial electric double layers. The incomplete semicircular arc at the high frequency region is attributed to the measuring limitation of the electrochemical workstation $(\leq 1$ $\mathrm{MHz}$ ). The passages for oxygen ion transfer through the polycrystalline electrolyte involve the grains and the grain boundaries. Accordingly, the response process of the ionic conductor under AC signal is fitted with the equivalent circuit in Fig. 2: $R_{\mathrm{g}}, R_{\mathrm{b}}$ and $R_{\mathrm{i}}$ symbolizes grain resistance, grain boundary resistance and electrode/electrolyte interfacial resistance respectively (All resistance elements denote area resistances.). $Q_{1}$ and $Q_{2}$ were the constant phase elements which are related to the double layer capacitance at the grain boundary and the phase interface respectively. 


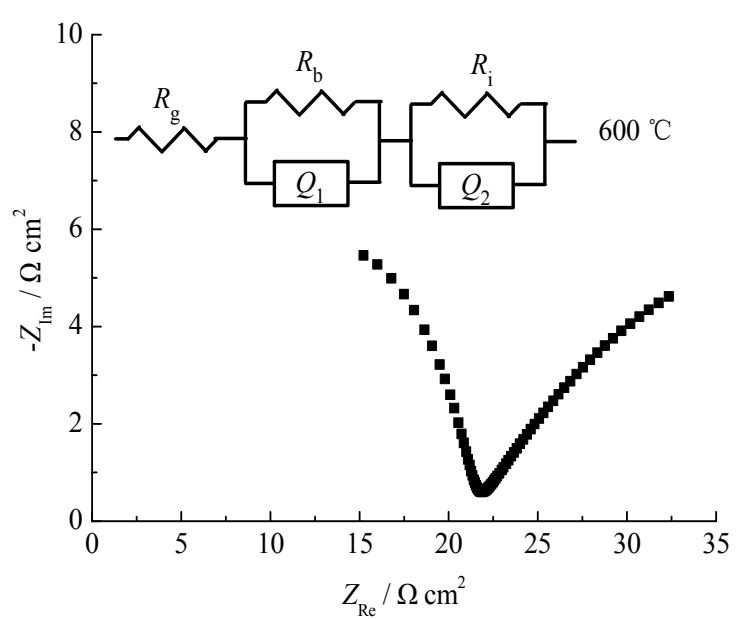

(a)

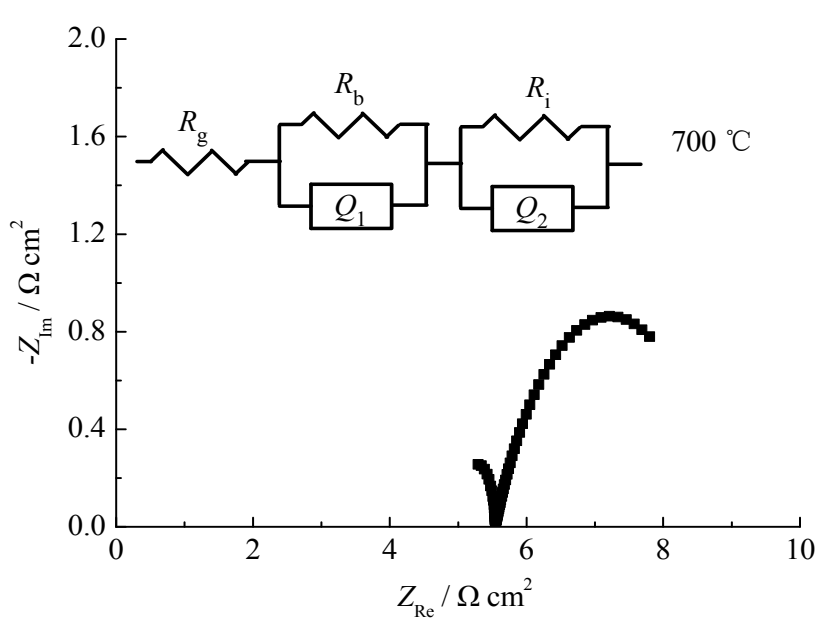

(c)

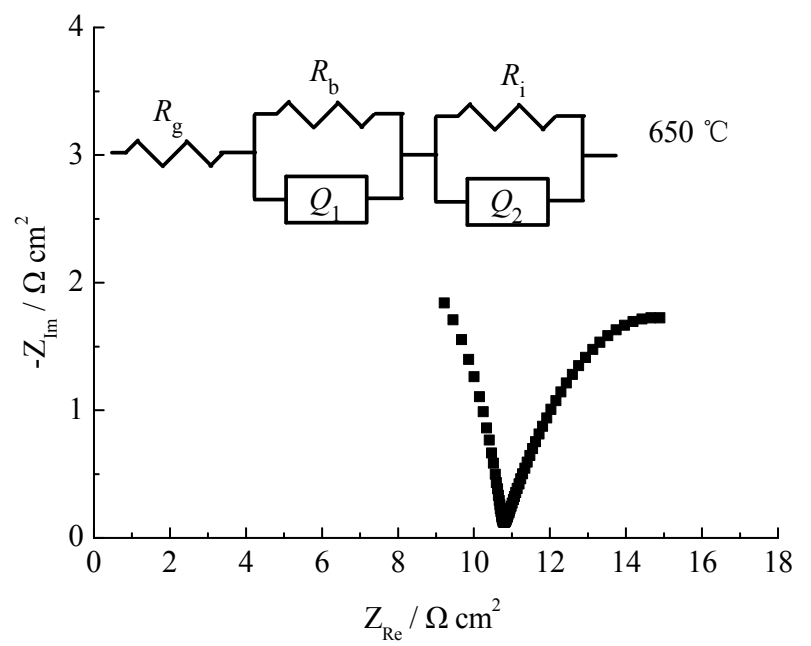

(b)

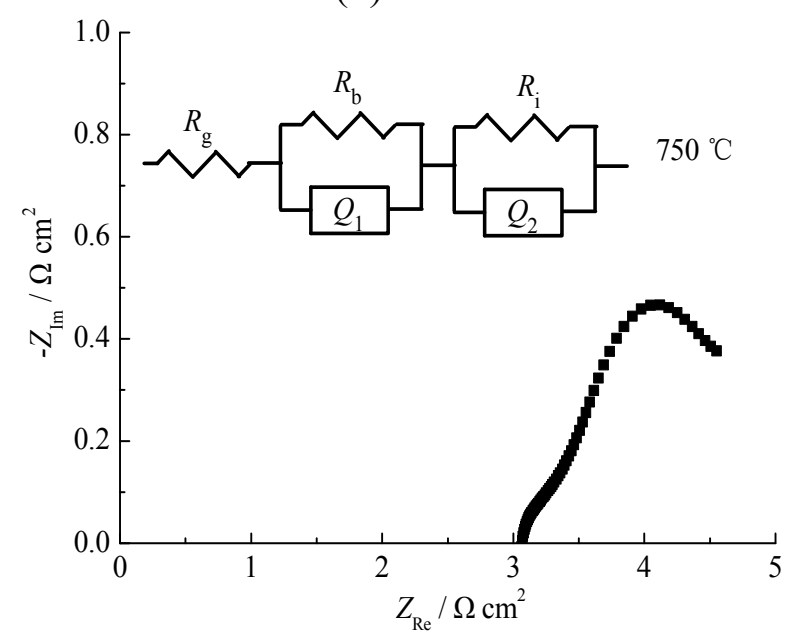

(d)

Fig. 2 Nyquist diagrams of SDC electrolyte at different temperatures, (a) $600{ }^{\circ} \mathrm{C}$, (b) $650{ }^{\circ} \mathrm{C}$, (c) $700{ }^{\circ} \mathrm{C}$, (d) $750{ }^{\circ} \mathrm{C}$

The ionic conductivity $(\sigma)$ can be obtained according to Equation (1), in which $\delta$ represents the thickness of the SDC substrate. The correlation between the ionic conductivity and the operation temperature is represented in Table. 1 . It is noteworthy that an ionic conductivity of $0.029 \mathrm{~S} \mathrm{~cm}^{-1}$ is achieved at $750{ }^{\circ} \mathrm{C}$.

$$
\sigma=\frac{\delta}{\left(R_{\mathrm{g}}+R_{\mathrm{b}}\right)}
$$

Table 1 Electrical performance of SDC electrolyte vs. temperature

\begin{tabular}{cccc}
\hline$T /{ }^{\circ} \mathrm{C}$ & $R_{\mathrm{g}} / \Omega \mathrm{cm}^{2}$ & $R_{\mathrm{b}} / \Omega \mathrm{cm}^{2}$ & $\sigma / \mathrm{S} \mathrm{cm}^{-1}$ \\
\hline 600 & 5.63 & 15.7 & 0.0047 \\
650 & 4.83 & 5.90 & 0.0093 \\
700 & 4.42 & 3.96 & 0.012 \\
750 & 2.90 & 0.550 & 0.029 \\
\hline
\end{tabular}

The substitution of $\mathrm{Sm}$ for $\mathrm{Ce}$ in $\mathrm{CeO}_{2}$ fluorite structure can be depicted by Equation (2). For the electroneutral condition, the concentrations of the defects satisfy the Equation (3).

$$
\begin{aligned}
& \mathrm{Sn}_{2} \mathrm{O}_{3} \stackrel{\mathrm{CeO}_{3}}{\longrightarrow} 2 \mathrm{Sm}_{\mathrm{Ce}}^{\prime}+3 \mathrm{O}_{0}^{\mathrm{x}}+\mathrm{V}_{0}^{*} \\
& 2\left[\operatorname{Sn}_{\mathrm{Cu}}^{\prime}\right]=\left[\mathrm{V}_{0}^{\cdot \cdot}\right]
\end{aligned}
$$

The polycrystalline synthesized via sol-gel method involves abundant grain boundaries due to the small grain size. Compared to the grain, the grain boundary region with a looser atomic arrangement 
favors the transfer of the carriers. At the relatively high temperature, the binding effect of the dopant anions to the oxygen vacancies weakens due to the active thermal motion. As a result, the oxygen vacancies migrate to the grain boundary region. Thus, the grain boundary resistance falls sharply with the increase of the operation temperature. Therefore, the structural change of the grain boundary plays an important role in promoting the oxygen ionic conductivity. Accordingly, submicron SDC powder shows a potential application prospect as the intermediate-temperature for automobile oxygen sensor.

\section{Conclusions}

Nano-sized $\mathrm{Ce}_{0.8} \mathrm{Sm}_{0.2} \mathrm{O}_{1.9}$ material was synthesized through a citric acid sol-gel method for the intermediate-temperature electrolyte of automobile oxygen sensor. XRD analysis indicated that the partial substitution of Ce by Sm in the lattice. The SDC-based electrolyte exhibited an oxygen ionic conductivity of $0.029 \mathrm{~S} \mathrm{~cm}^{-1}$ at $750{ }^{\circ} \mathrm{C}$. The improvement of electrical performance benefited from the small crystal size and the enrichment of oxygen vacancies at the grain boundaries.

\section{Acknowledgements}

This work was financially supported by Natural Science Foundation of Hunan Province (12JJ6015), International Cooperation Plan of Hunan Department of Science \& Technology (2012WK3024), and Construct Program of Key Discipline in Hunan Province.

\section{References}

[1] B. Elyassi, N. Rajabbeigi, A. Khodadadi, S. S. Mohajerzadeh and M. Sahimi. Sensor. Actuat. B: Chem. Vol. 103 (2004), p. 178.

[2] S. Gupta, S. V. N. T. Kuchibhatla, M. H. Engelhard, V. Shutthanandan, P. Nachimuthu, W Jiang, L. V. Saraf, S. Thevuthasan and S. Prasad. Sensor. Actuat. B: Chem. Vol. 139 (2009), p. 380.

[3] N. S. Xu, X. Li, X. Zhao, H. L. Zhao and K. Huang. Eletrochem. Solid St. Vol. 15 (2012): p. B1.

[4] C. Huang, D. J. Chen, Y. Lin, R. Ran and Z. P. Shao. J. Power Sources Vol. 195 (2010), p. 5176.

[5] P Jasinski. Solid State Ionics Vol. 177 (2006), p. 2509.

[6] T. Shimonosono, Y. Hirata, Y. Ehira, S. Sameshima, T. Horita and Y. Harumi. Solid State Ionics Vol. 174 (2004), p. 27.

[7] A. P. Khandale and S. S. Bhoga. Solid State Ionics Vol. 182 (2011), p. 82.

[8] D. C. Chen, J. F. Wu, Y. Q. Liang, S. L. Ye and W. F. Li. T. Nonferr. Metal. China Vol. 21 (2011), p. 1905.

[9] S. A. Acharya. J. Power Sources. Vol. 198 (2012), p. 105.

[10]Y. Liu, C. Wen, Y. Guo, G. Z. Lu and Y. Q. Wang. J. Mol. Catal. A: Chem. Vol. 316 (2010), p. 59.

[11]E. V. Tsipis, E. N. Naumovich, M. V. Patrakeev, A. A. Yaremchenko, I. P. Marozau, A. V. Kovalevsky, J. C. Waerenborgh and V. V. Kharton. Solid State Ionics Vol. 192 (2011), p. 42.

[12] P. P. Dholabhai, S. Anwar, J. B. Adams, P. Crozier and R Sharm. J. Solid Stat. Chem. Vol. 184 (2011), p. 811.

[13] N. A. Hardan, M. J. Abdullah and A. A. Aziz. Appl. Surf. Sci. Vol. 257 (2011), p. 8993.

[14] V. Radmilovic, H. A. Gasteiger and P. N. Ross. J. Catal. Vol. 154 (1995), p. 98. 